\title{
Inspeção e análise das manifestações patológicas na ponte sobre o Rio Canindé, no Piauí.
}

\author{
T. B. M. Alves ${ }^{1 *}$, L. O. Bento ${ }^{1}$, A. R. O. Dias ${ }^{1}$ \\ *Autor de Contacto: thamilaalves1@aluno.uema.br \\ ${ }^{1}$ Departamento de Ciências Exatas e Naturais, Universidade Estadual do Maranhão, Bacabal, Brasil
}

\begin{abstract}
RESUMO
O presente estudo teve como foco uma discussão acerca das patologias em pontes de concreto armado, enfatizando um estudo de caso realizado em uma ponte sobre o Rio Canindé, no estado do Piauí, Brasil. A estrutura se mostrou um alvo de estudo necessário quando sofreu um colapso parcial, com a queda de 12 metros de sua proteção lateral. Dessa forma, através de inspeção e análise visual, buscou-se constatar o real estado da ponte e avaliar quais as principais manifestações patológicas estão comprometendo a estrutura. A inspeção permitiu identificar fissurações na superestrutura, desgastes nas juntas de dilatação, deterioração do concreto da fundação e infiltrações. Constatou-se que toda a estrutura necessita de intervenções de reparo imediatas, a fim de evitar novos colapsos.
\end{abstract}

Palavras-chave: Obras Rodoviárias; Patologias; Concreto Armado; Deterioração. 


\begin{abstract}
The present study focused on a discussion about pathologies in reinforced concrete bridges, emphasizing a case study carried out on a bridge over Canindé River, in state of Piauí, Brazil. The structure proved to be a necessary study target when it partially collapsed, with the 12 meter collapse of its side protection. Thus, through inspection and visual analysis, aimed to verify the real state of the bridge and evaluate which main pathological manifestations are compromising the structure. The inspection allowed the identification of cracks in the superstructure, degraded expansion joints, concrete foundation deterioration and infiltrations. Realizing that the entire structure needs immediate repair interventions in order to avoid further collapse.
\end{abstract}

Keywords: Road Works; Pathologies; Reinforced Concrete; Deterioration.

\title{
RESUMEN
}

El presente estudio se centró en una discusión sobre patologías en puentes de hormigón armado, enfatizando un estudio de caso realizado en un puente sobre el río Canindé, en el estado de Piauí, Brasil. La estructura resultó ser un objetivo de estudio necesario cuando colapsó parcialmente, con el colapso de 12 metros de su protección lateral. Así, mediante inspección y análisis visual, se tuvo como objetivo verificar el estado real del puente y evaluar qué principales manifestaciones patológicas están comprometiendo la estructura. La inspección permitió identificar fisuras en la superestructura, juntas de dilatación degradadas, deterioro de cimientos de hormigón e infiltraciones. Al darse cuenta de que toda la estructura necesita intervenciones de reparación inmediatas para evitar un mayor colapso.

Palabras clave: Obras Viales; Patologías; Hormigón Armado; Deterioro.

\section{INTRODUÇÃO}

O senso comum de durabilidade infinita que cerca as pontes é habitual na sociedade e, segundo Vitório (2002), está associado à robustez e solidez presente nestas obras, no entanto, acrescenta 
que as pontes, assim como outras edificações, estão à mercê da deterioração a partir do momento que são postas em funcionamento, onde seu ciclo de vida depende das condições de uso, conservação e manutenção ao longo do tempo.

Considerando tais aspectos, a visão geral das pontes no Brasil é apontada por Euqueres (2011) quando afirma que as pontes e os viadutos começaram a ser construídas a partir das décadas de 70 e 80, onde várias das manifestações patológicas apresentadas nestas obras vêm de práticas construtivas não condizentes com a eficácia de qualidade da atual realidade, a falta de especificações e a falta de manutenção.

No viés de conservação das pontes, Vitório (2002) acrescenta que inspeções objetivando manutenções preventivas e corretivas devem fazer parte do plano de gestão das rodovias, onde vistorias periódicas sejam feitas no sentido de identificar as falhas estruturais e apresentar as ações de recuperação necessárias. No entanto, com relação ao contexto construtivo brasileiro atual, Vitório (2002) acrescenta que há a falta de uma cultura de manutenção, principalmente a preventiva, onde os setores públicos responsáveis por estas obras não se preocuparam ao longo do tempo em definir políticas e estratégias para a conservação das pontes.

No intuito de viabilizar a segurança, funcionalidade e durabilidade com o menor custo possível, Vitório (2002) afirma que estudos e pesquisas feitas nas últimas décadas aferem a importância de sistemas que objetivam a gestão de pontes, e com isso apoia a adoção desses sistemas no Brasil pelos órgãos responsáveis por sua conservação, onde a partir deles permite-se tomar decisões rápidas e eficazes baseadas em parâmetros técnicos e científicos voltados para a otimização dos custos de manutenção e um menor desperdício de verbas advindas do dinheiro público, ou seja, os maiores beneficiários é a sociedade em geral.

Logo, destacando a importância de inspeções em pontes para aferir as suas necessidades de manutenções e garantir a devida durabilidade e segurança, este trabalho tem como objetivo apresentar um estudo de caso acerca de uma ponte sobre o rio Canindé, no estado do Piauí, adotando uma metodologia baseada em inspeção visual, fotográfica e revisões bibliográficas, para que se fosse possível destacar as manifestações patológicas apresentadas na ponte e as possíveis causas de sua aparição.

\section{REFERENCIAL}

\subsection{Elementos estruturais da ponte}

As pontes são construções importantes para o desenvolvimento de uma região, uma vez que garante a continuidade de uma via. Segundo Debs e Takeya (2007), a ponte é uma estrutura, cuja finalidade é transpor um obstáculo sobre um curso d’água ou superfície líquida. A estrutura de uma ponte deve ser dimensionada e analisada mediante cenário em que a mesma será construída, sendo uma construção composta por infraestrutura, mesoestrutura e superestrutura.

De acordo com Sartorti (2008), a superestrutura é a parte que tem como objetivo vencer o obstáculo e pode ser dividida em estrutura principal, vigas e longarinas, e em estrutura secundária, tabuleiro, tábuas ou chapas metálicas, que recebe diretamente as ações dos carregamentos. A mesoestrutura é composta pelos elementos intermediários, como os pilares e encontro, que tem função de suportar os carregamentos e transferir para a infraestrutura. A infraestrutura é composta pelos elementos de fundação, como os blocos, estacas e tubulões, que transmitem as cargas ao solo. Para Sartorti (2008), ainda há os elementos responsáveis por transmitir os carregamentos e suportar os deslocamentos da superestrutura, que são os aparelhos de apoio.

Ao projetar uma ponte deve-se levar em conta algumas considerações das condições de uso, garantindo manutenção para evitar-se a paralisação da via. Para analisar as manifestações patológicas em estruturas de pontes é necessário entender os motivos dos surgimentos e procurar 
meios de solucionar as causas. Dessa forma, para que a análise dos efeitos patológicos seja fidedigna, é essencial buscar a origem do problema para poder realizar os reparos e garantir a durabilidade da estrutura.

Para melhor entendimento Laner (2001) aponta que por pontes serem construções de custo elevado, tanto para construção como para a recuperação, a intervenção deve ser bem planejada, visto que para isso origina-se impasses econômicos e sociais. Com isso, ações preventivas são necessárias para evitar possíveis complicações e até colapso da estrutura.

As manifestações patológicas em uma estrutura, podem surgir por alguns fatores, para Souza e Ripper (2005), esses fatores podem estar presentes na fase de execução de alguma etapa da obra, assim como no controle de qualidade da construção.

\subsection{Manifestações patológicas em obras de concreto armado (fundação, junta, muro)}

A ocorrência de patologias em obras de concreto armado tem gerado muitos estudos. Silva et. al (2018) aponta que manifestações patológicas podem ser geradas por diversos fatores, dentre eles destaca-se falha na execução, envelhecimento da estrutura, acidentes e irregularidade em manutenções, sendo que a estrutura deve oferecer durabilidade e desempenho.

Dessa forma, com obras em estado crítico de conservação, onde não há manutenções, acompanhamento da estrutura ou vistorias das manifestações apresentadas, o cenário aponta para estruturas com risco de colapso, acarretando tanto em ameaças para a sociedade como em prejuízos financeiros.

As manifestações patológicas em fundações das estruturas, segundo Milititsky et. al (2015), podem acontecer devido falhas em projetos, onde abrange o reconhecimento do solo e o comportamento do mesmo com a aplicação das cargas, no processo construtivo e quando a obra é finalizada com a possibilidade de degradação dos elementos. Além disso as fundações de pontes, por serem submersas, podem apresentar patologias devido a oscilações no nível de água não previstas em projeto, por exemplo quando ocorre rebaixamento do nível de água, podendo gerar erosão e solapamento nas fundações. Por se tratar de uma estrutura em concreto armado, esses fatores podem comprometer consideravelmente a estrutura, sendo que com a degradação do concreto e a armadura exposta em meio agressivo, gera a corrosão e perda das propriedades mecânicas dos elementos.

De acordo com a pesquisa de Pinheiro e Silva (2018) observou-se que as manifestações patológicas mais recorrentes em estruturas de pontes de concreto armado são as fissuras, desagregação de concreto, eflorescência e corrosão da armadura. Pode-se notar que essas manifestações podem ser provocadas pela intensa agressividade do ambiente da construção, utilização de materiais inadequados, erros técnicos e falta de manutenção, podendo comprometer diversos elementos da ponte. De acordo com NBR 7187/2003 as juntas de dilatação são os elementos responsáveis pela movimentação da estrutura e realização da vedação do local, o seu dimensionamento deve ser detalhado no projeto estrutural. Dessa forma, observa-se que as juntas quando comprometidas por alguma manifestação patológica pode comprometer a estrutura tanto por falha de movimentação como infiltração. A literatura aborda que manifestações patológicas em juntas de dilatação são provocadas por diversos fatores como a movimentação das formas, mau detalhamento no projeto, corrosão do concreto e ataques biológicos.

Estruturas de pontes estão submetidas tanto aos esforços mecânicos, proveniente do tráfego ou ocorrência de choques em casos de acidentes, como aos esforços devido ao ambiente em que a estrutura é construída, como ação do vento, tendo que considerar os esforços de massa de solo e inundações.

O muro de contenção nas pontes são os responsáveis por conter a massa de solo nas encostas, evitando o movimento de solo e garantindo a segurança da estrutura. A NBR 7187/2003 determina 
que o empuxo de terra em estruturas de pontes seja determinado mediante as propriedades do solo, a partir das características do terreno, indicando as inclinações e os parâmetros que devem ser considerados. Ainda de acordo com a norma, quando os elementos de contenção estão inseridos na superestrutura, a ação do empuxo de terra deve ser considerada no dimensionamento, podendo contribuir nos esforços dos quais os elementos devem resistir.

O empuxo da água é um esforço que deve ser considerado nos elementos de contenção. A NBR $7187 / 2003$ considera que o empuxo da água e a subpressão devem ser majoradas nas piores situações, sendo que em períodos chuvosos o nível de água aumenta e com isso as cargas nos elementos estruturais.

Os muros de contenções em pontes devem ser dimensionados com bases nos esforços mecânicos e naturais da estrutura. Manifestações patológicas nestes elementos são caracterizadas pelos movimentos de terras, deterioração das estruturas e comprometimento da estabilidade da ponte, uma vez que o muro de contenção é responsável por conter a massa de solo e garantir a estabilidade. Um muro de contenção muito comum em estruturas de pontes é o muro de gabião, construído por gaiolas de aço e colocação de pedra. Esse tipo de muro permite a passagem de água, no entanto, contém a massa de solo. No muro de gabião pode surgir patologias por alguns fatores, entre eles, a corrosão dos fios de aço e rompimento dos mesmos, fazendo com que desabe a estrutura de pedras e comprometa a estrutura, e por movimentações de solo não previstas pelo dimensionamento do muro, com isso a estrutura não suporta os esforços e pode vir a colapso.

\subsection{Inspeção}

A preservação da estrutura de uma ponte é garantida mediante intervenções necessárias para garantir a funcionalidade e desempenho, onde passam por uma série de análises e por fim são determinadas quais manutenções devem ser adotadas. Souza e Ripper (2005) tratam de manutenção como uma série de intervenções a fim de suprir o desenvolvimento da estrutura ao longo do tempo, ou seja, são atividades das quais as estruturas necessitam para manter a integridade.

Vitório (2002) afirma que nas inspeções realizadas em pontes deve haver rigorosa observação em todos os elementos da estrutura. Onde deve ser adotado um roteiro, fazendo com que realize anotações de todas as considerações necessárias para identificação dos problemas. Além disso, devem ser feitos registros fotográficos a fim de contribuir para o relatório final da inspeção e colaborar nas identificações das avarias existentes na obra. Vitório (2002) divide as inspeções em duas etapas, sendo a primeira o exame local da obra e a segunda a análise do projeto original, as modificações e o relatório final, realizando a investigação os elementos da infraestrutura, mesoestrutura, superestrutura, acabamentos e acessos.

Outro método de inspeção é apresentado pelo DNIT 010/2004 que especifica os procedimentos gerais sistemáticos que garantem a necessidade de fichas de inspeção, registros fotográficos abrangendo todas as manifestações patológicas, todas as vistas, assim como os detalhes de apoios, juntas e etc., acrescentando a necessidade de observar a ponte na passagem de cargas pesadas para possibilitar a verificação da existência ou não de vibrações ou deformações excessivas. Somado a isto, o DNIT 010/2004 também especifica os procedimentos particulares de uma inspeção, onde aconselham a observação de: geometria e condições viárias, acessos, cursos d'água, encontros e fundações, apoios intermediários, aparelhos de apoio, superestrutura, pista de rolamento, juntas de dilatação, barreira e guarda-corpos, sinalização e instalações de utilidade pública.

Além do já que já foi apresentado, é importante destacar que o DNIT 010/2004 divide as inspeções em 5 tipos: inspeção cadastral, é a primeira a ser realizada em uma ponte, sendo preferencialmente executada logo após a construção; inspeção rotineira, é periódica e realizada a cada dois anos; inspeção extraordinária, não programada e é solicitada para avaliação de um dano estrutural 
imprevisto; inspeção especial, são visuais e minuciosas com relação aos detalhes; e a inspeção intermediária, feitas para monitorar alguma manifestação patológica.

\section{METODOLOGIA}

O presente estudo foi realizado em uma ponte sobre o rio Canindé, representada na Figura 1, que possui extensão de 170 metros e largura de 8 metros, localizando-se na BR-230, entre as cidades de Oeiras-PI e Picos-PI, no Brasil. Tal ponte foi construída em 1968, e é caracterizada por possuir um traçado retilíneo e perpendicular ao curso do rio (Figura 2), sendo o concreto armado o sistema construtivo adotado em sua execução.

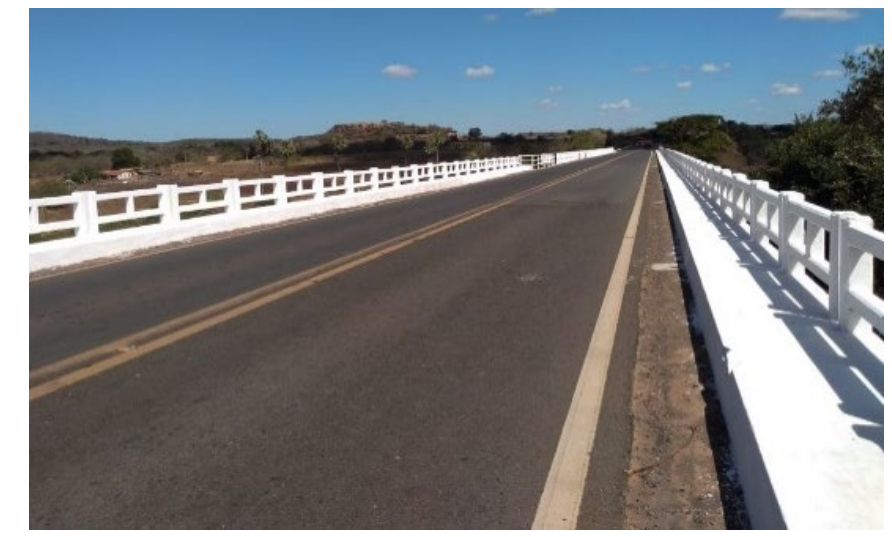

Figura 1. Traçado da ponte sobre o Rio Canindé.

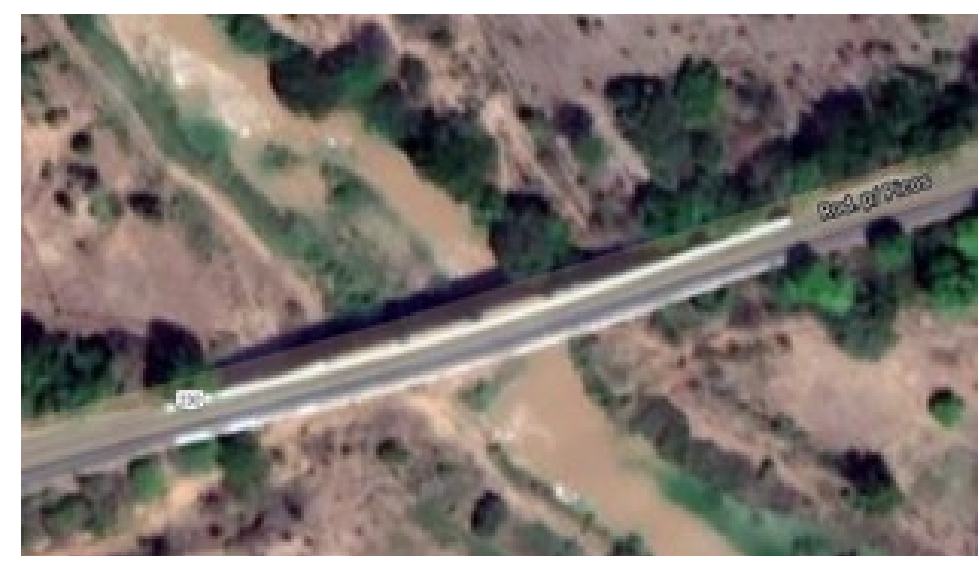

Figura 2. Localização da ponte sobre o Rio Canindé.

No entanto, relata-se que após o incidente não houve o reparo devido da estrutura da ponte, sendo constatado apenas a inserção de uma proteção de madeira (guarda-corpo) cercando a parte que sofreu o colapso, supondo-se que tal ação seja para que não haja mais acidentes neste local (Figura 5), meses após o acontecimento pode ser observado a armadura exposta do tabuleiro da ponte, representado na Figura 6. 


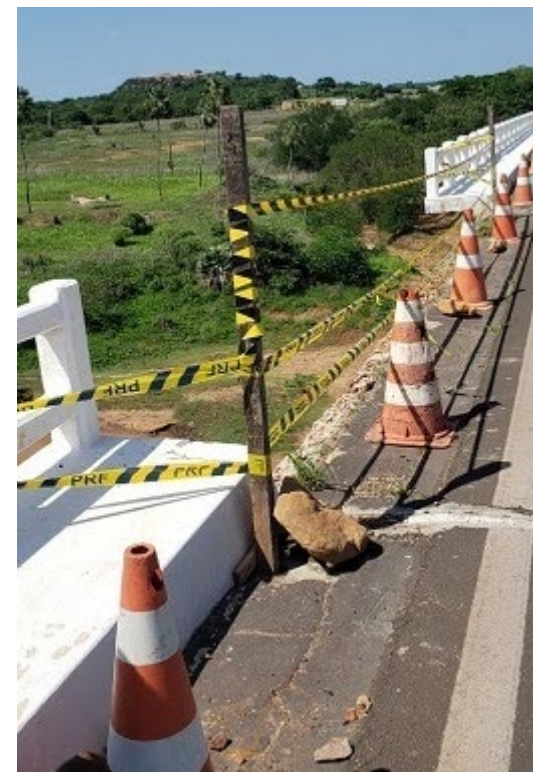

Figura 3. Registros fotográficos do acidente ocorrido na ponte.

Fonte: Valentim (2020)

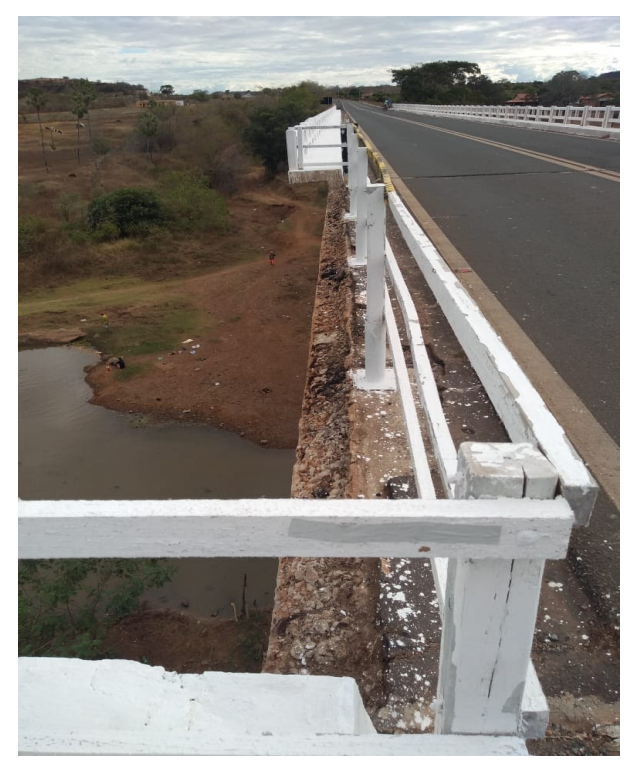

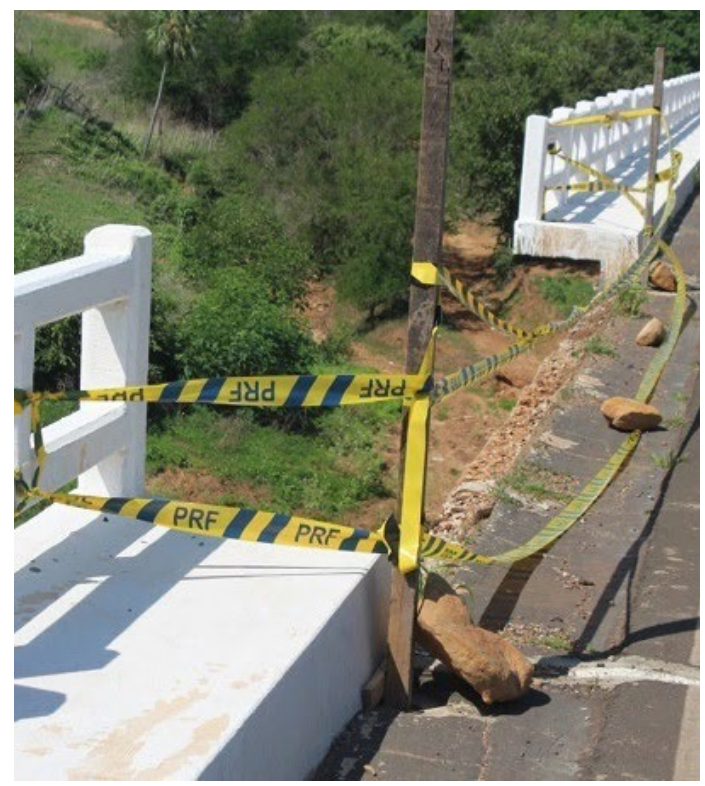

Fonte: Valentim (2020)

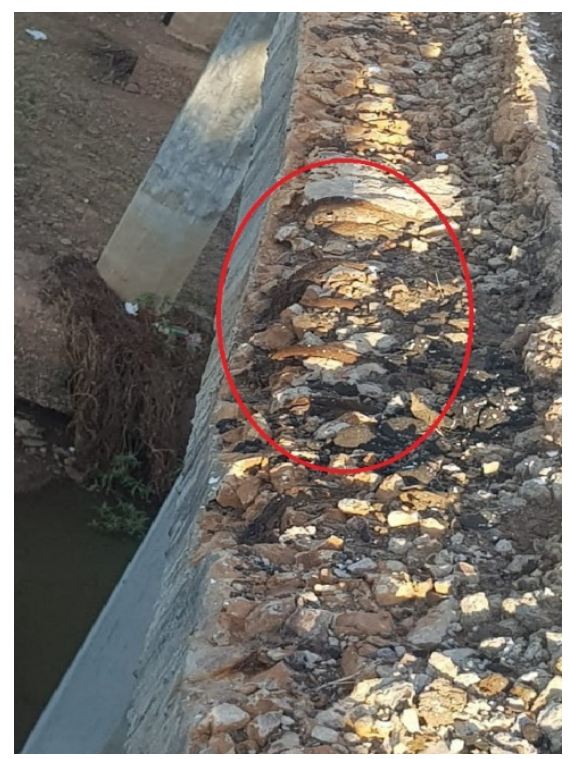

Figura 6. Armadura exposta no tabuleiro da ponte.

Tendo isto em mente, tal artigo tem por objetivo uma análise visual desta ponte, onde discutirá as manifestações patológicas encontradas após a inspeção, registradas por meio de fotografias. 
elementos da ponte. Posteriormente, realizou-se pesquisas bibliográficas objetivando o estudo acerca de pontes e suas principais manifestações patológicas, assim como seus mais frequentes agentes degradadores, para poder ser aplicada na ponte em questão.

\section{RESULTADOS}

\subsection{Infraestrutura}

Alguns dos principais danos presenciados na ponte foi a degradação do bloco de coroamento, que possui uma altura de 1,40 metros e está completamente exposto, o bloco apresentou grande degradação do concreto na base, ninhos de concretagem, e armadura exposta. Na Figura 7, pode ser visualizado a indicação das manifestações patológicas nesse elemento da infraestrutura.

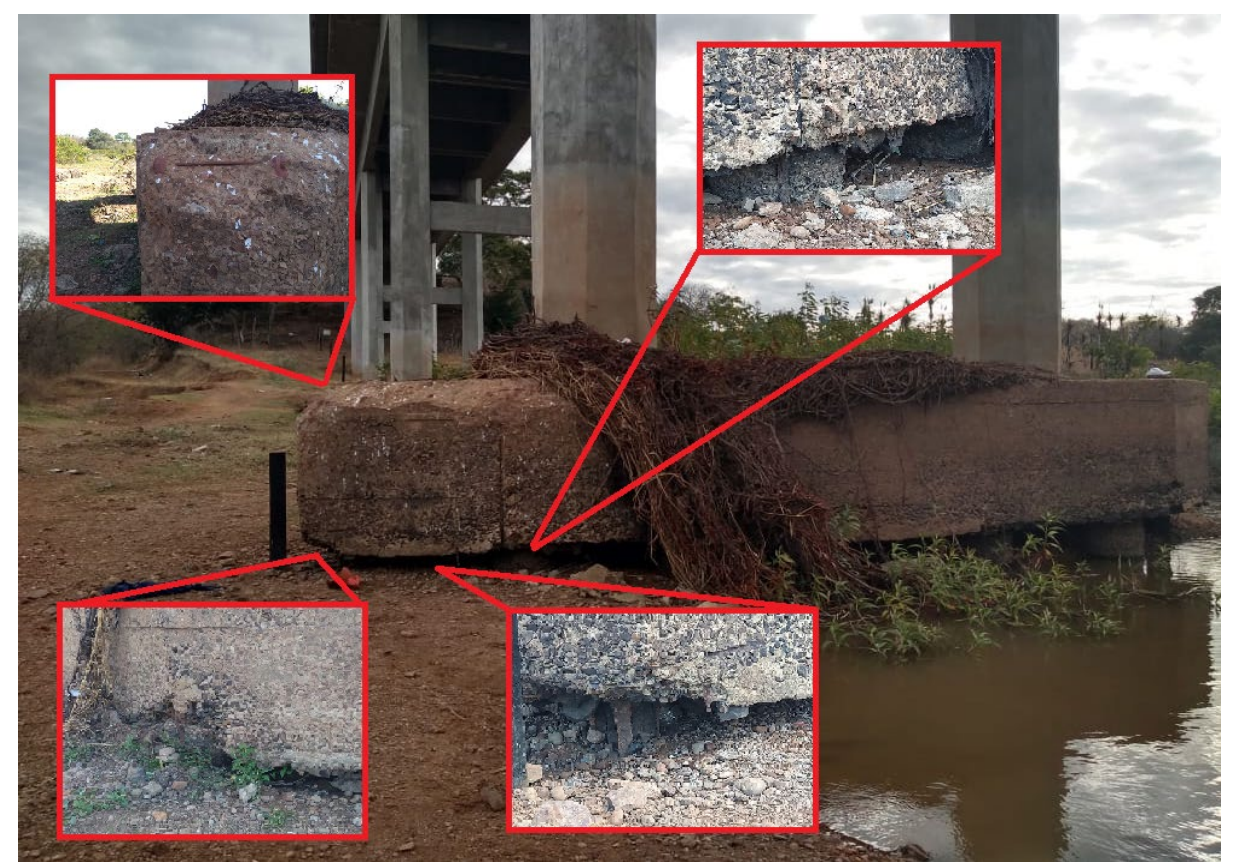

Figura 7. Mapeamento de manifestações patológicas na infraestrutura da ponte.

Os ninhos de concretagem na base da ponte podem ser observados na Figura 8, e geralmente são uma falha característica da etapa de execução, pode ser causado pelo lançamento e adensamento inadequado. Esses ninhos podem comprometer a estrutura pois acabam gerando vazios e sendo porta de entrada para agentes agressivos.

Observou-se nas estacas sob o bloco, a exposição e corrosão da armadura, onde tal elemento apresentou o diâmetro reduzido devido ao desgaste do concreto. Na Figura 8, pode ser observado as estacas expostas, esse fato pode implicar na redução da capacidade de carga, uma vez que os esforços são distribuídos no solo ao longo do contato lateral da estaca com este. Na Figura 8 também pode-se observar algumas manchas no concreto, tais efeitos podem ser originados por presença de fungos oriundos da retenção de umidade. $O$ desgaste do concreto na estaca pode ser visto na Figura 9, onde há a redução significativa do diâmetro da estaca. 


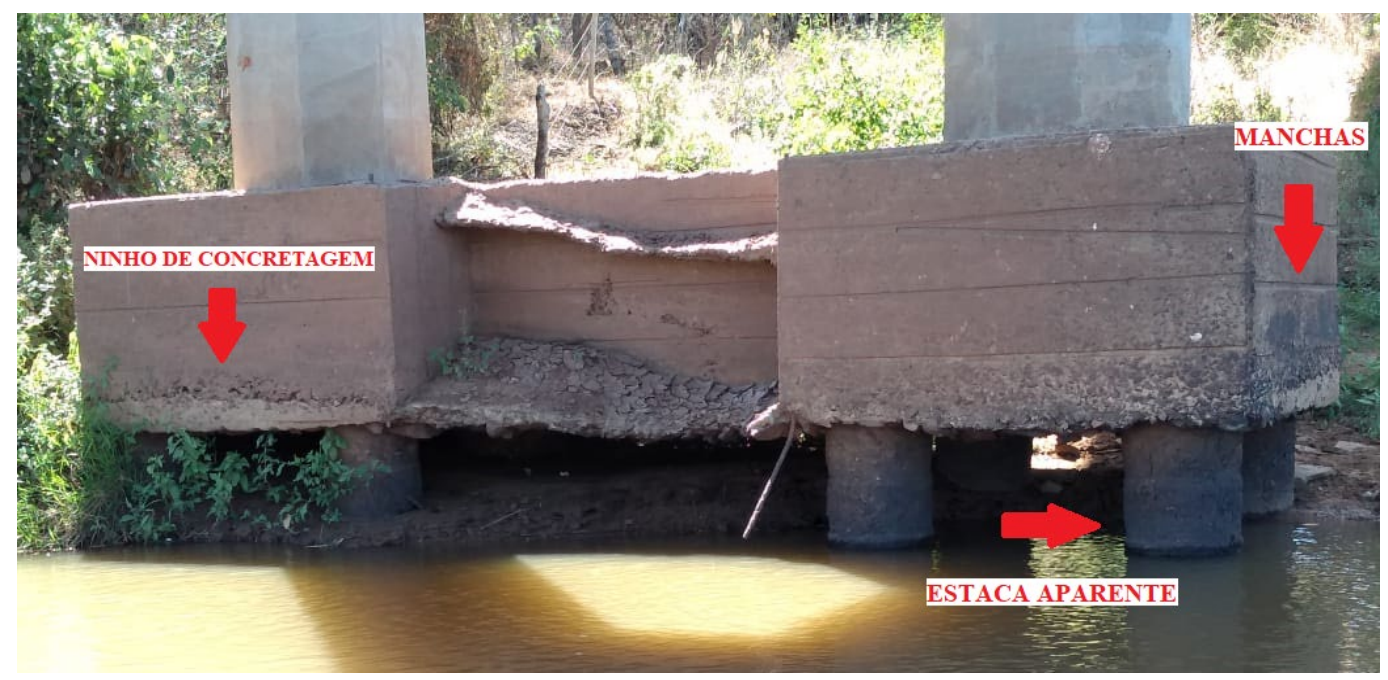

Figura 8. Indicação de manifestações patológicas no bloco de coroamento e estacas de fundação.

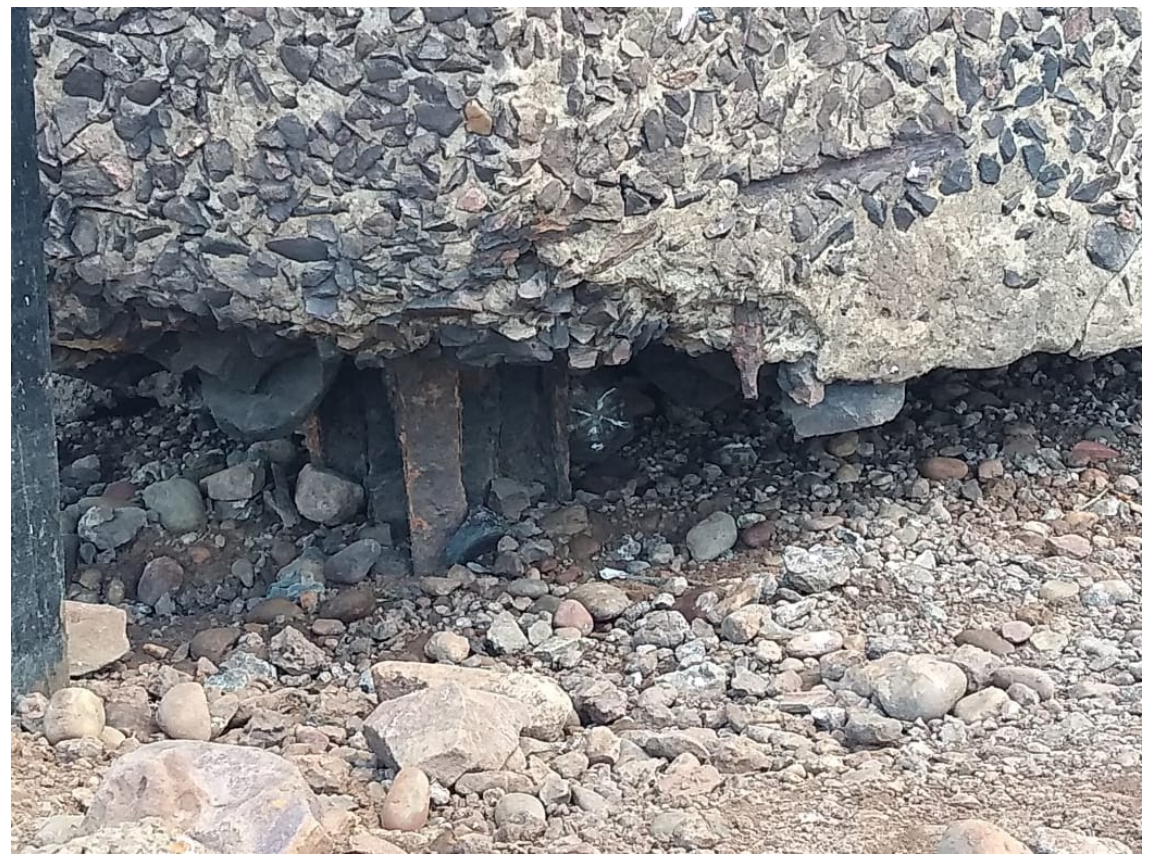

\subsection{Superestrutura}




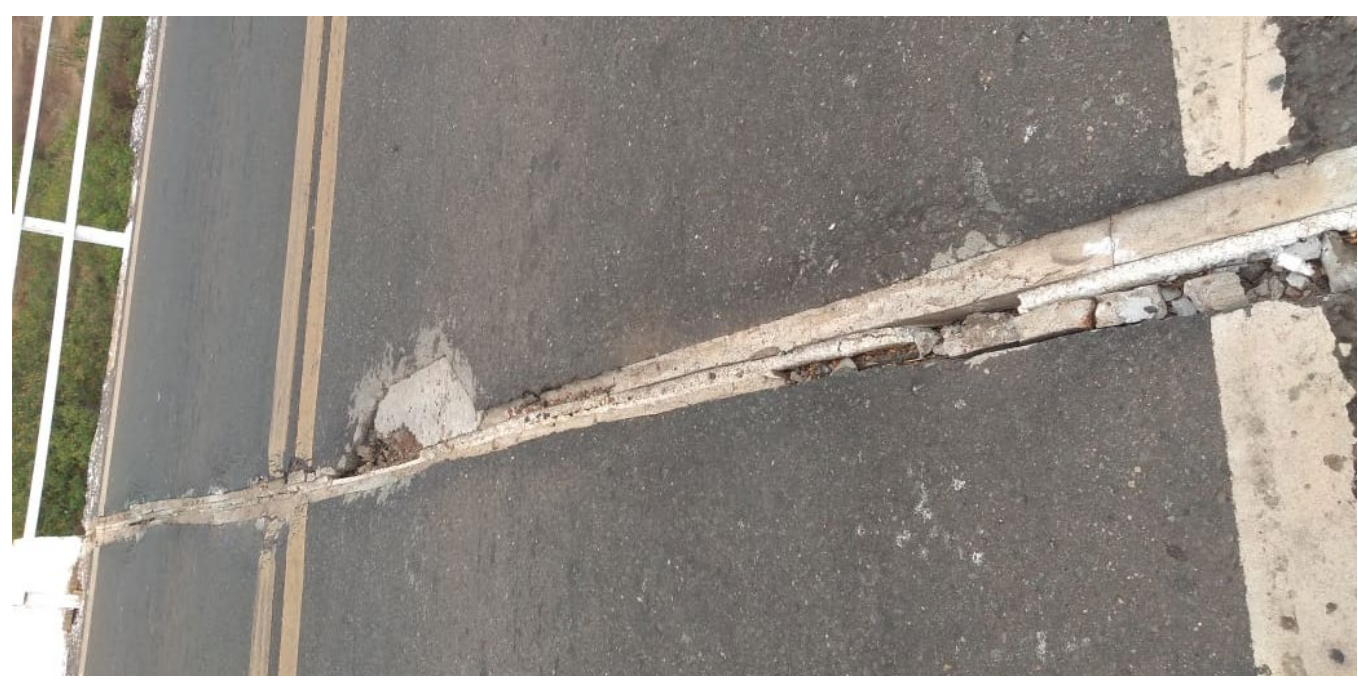

Figura 10. Rompimento do revestimento e aberturas na superestrutura.

Em conjunto a isto, na Figura 11, visualizou-se infiltrações na abertura das juntas do tabuleiro, o que pode ter sido ocasionado por uma falha de drenagem na superestrutura da ponte ocasionado por dreno danificado provocando infiltrações e manchas na laje. O sistema de drenagem também se encontra deteriorado, sem revestimento, podendo ter sido comprometido pela alta incidência de água, como pode ser visto na Figura 12.

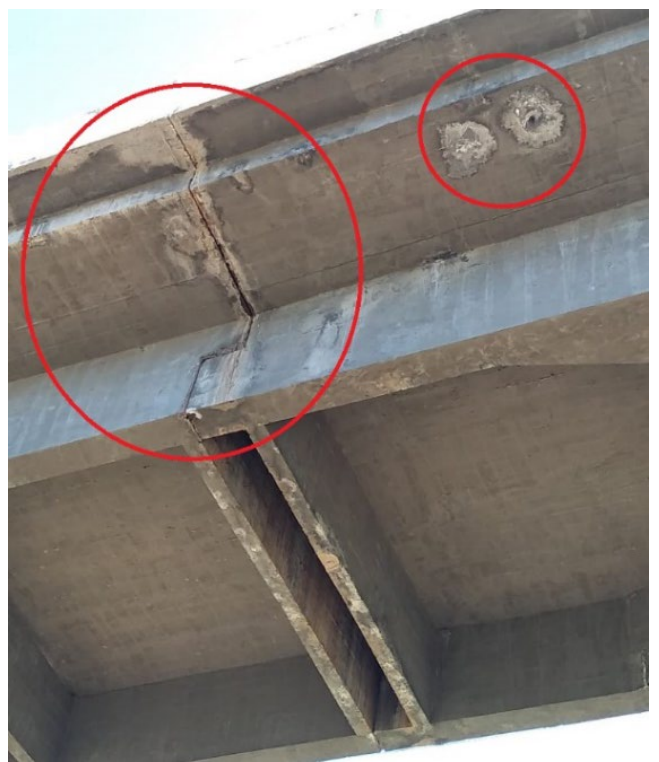

Figura 11. Infiltração no tabuleiro.

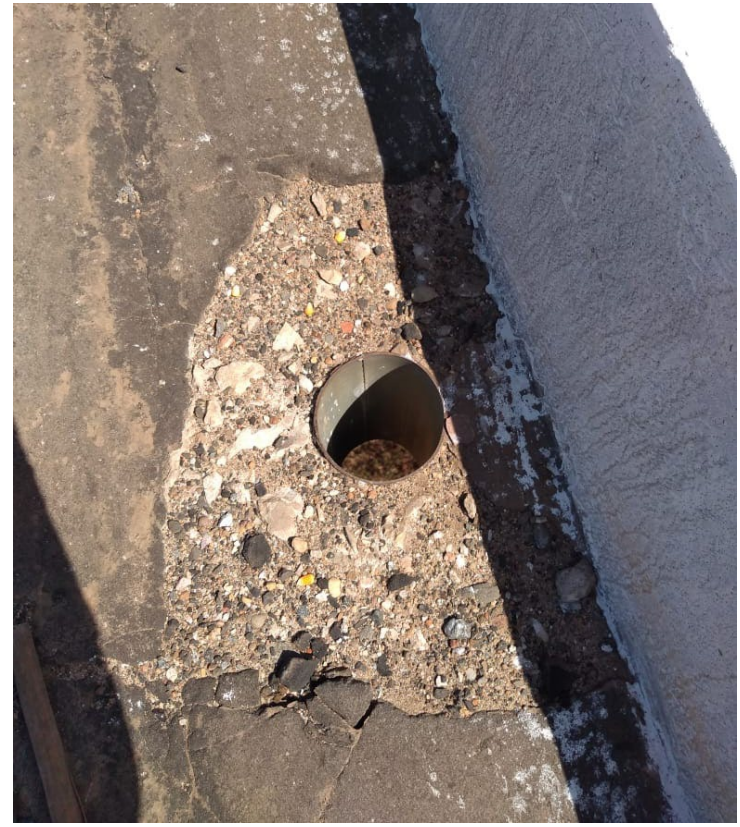

Figura 12. Dreno danificado.

\subsection{Muro de gabião}




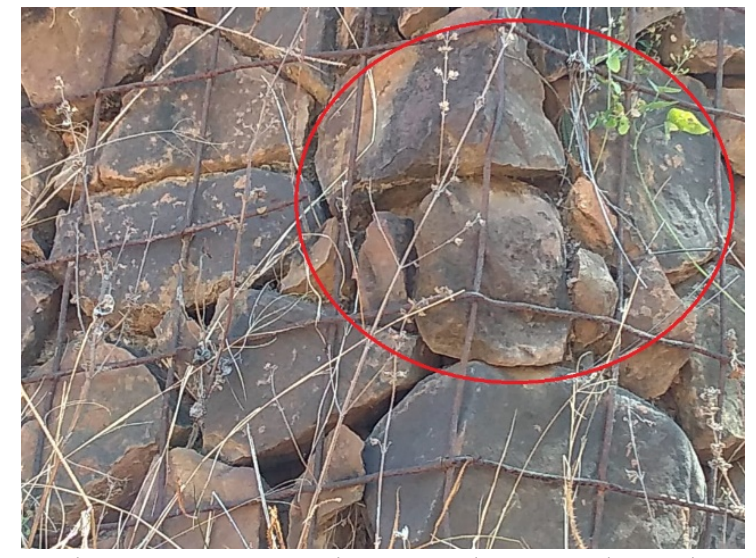

Figura 13. Rompimento da armadura do muro de gabião.

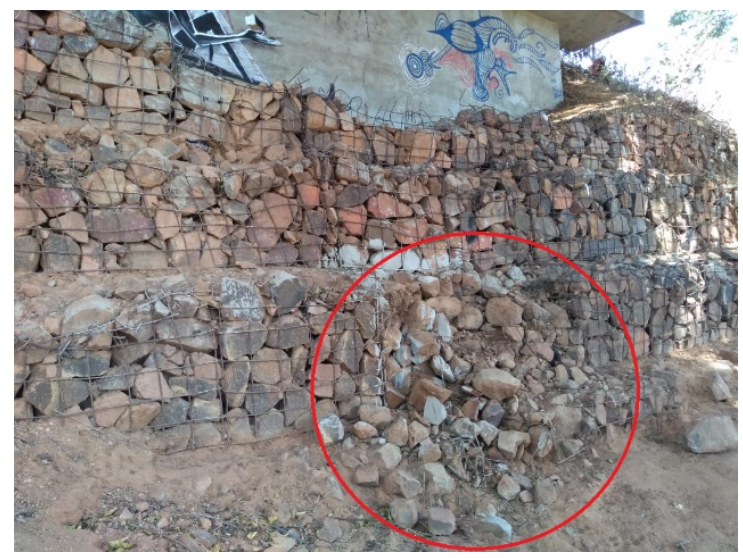

Figura 14. Desabamento de parte do muro de gabião.

\subsection{Mesoestrutura}

Um ponto muito interessante a se observar na estrutura da ponte é a variação no nível de água. A visita ao local foi realizada no período de estiagem, no mês de junho, entretanto, nos períodos de cheia do rio o nível da água chega a subir cerca 1,80 metros em relação ao período de estiagem, como pode ser visto na Figura 16, onde as marcas nos pilares são apontadas.

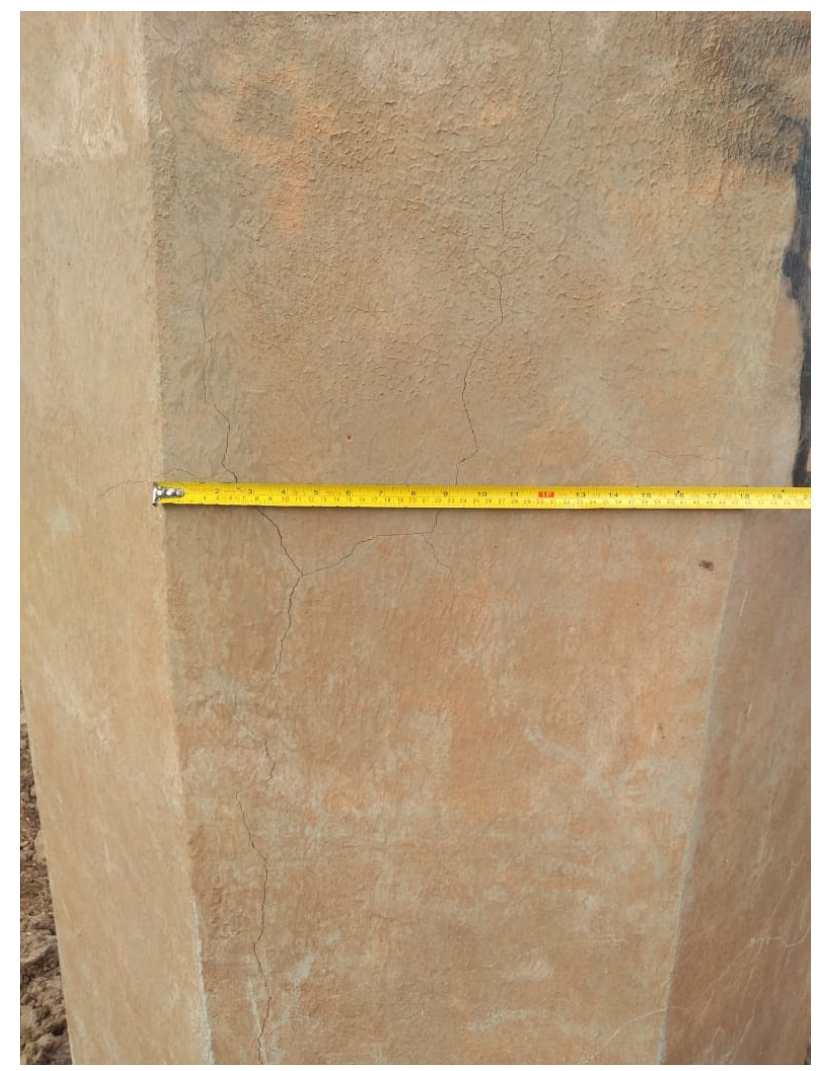

Figura 15. Fissuras em pilares da mesoestrutura. 


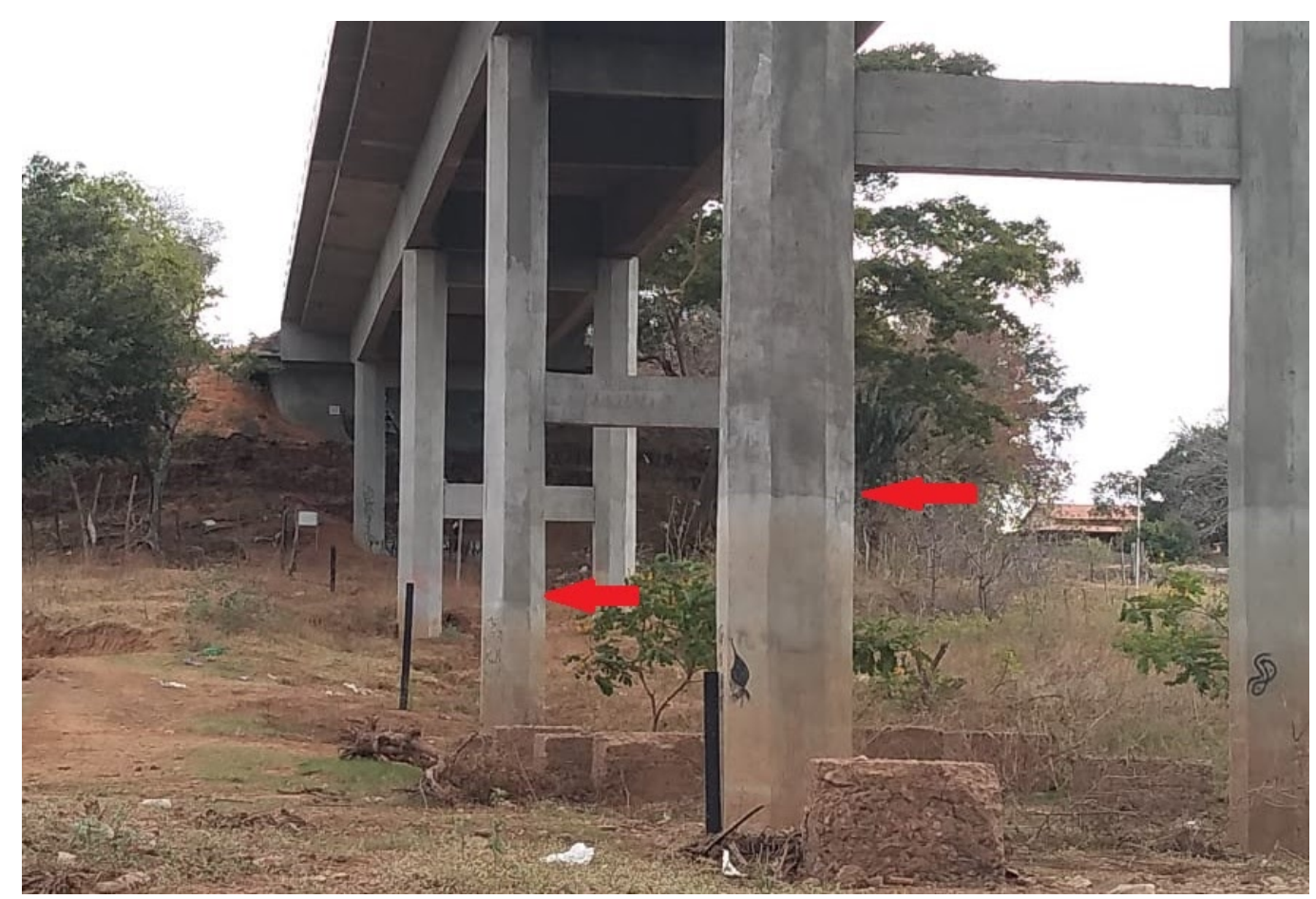

Figura 16. Indicação do nível de água nos períodos de cheia no rio.

\section{CONCLUSÃO}

As pontes, obras de arte especiais, compõem o sistema rodoviário brasileiro e apresentam papel significativo no cenário social e econômico. Acidentes envolvendo esse tipo de estruturas é um acontecimento recorrente devido à alta agressividade ambiental e a falta de manutenção da estrutura. Diante desse cenário, intervenções e inspeções técnicas são indispensáveis para que minimizem a quantidade de acidentes e garantam a durabilidade e segurança da estrutura.

Diante dessa situação, a inspeção realizada na ponte sobre o rio Canindé, constatou que as principais manifestações patológicas se encontram na infraestrutura, esses problemas estão relacionados com falha na execução e ausência de manutenções dos elementos estruturais que precisam de reforço.

Mediante as pesquisas bibliográficas observou-se que as pontes de concreto, devido ao meio agressivo em que as mesmas são construídas, estão sujeitas ao surgimento de manifestações patológicas, no entanto, se houver manutenções preventivas e correta execução dos elementos estruturais, consegue-se diminuir a incidência de avarias. Dessa forma, a manutenção das estruturas tem papel fundamental na integridade e durabilidade das mesmas. 


\section{REFERÊNCIAS}

Associação Brasileira de Normas Técnicas. (2003). NBR 7187: Projeto de pontes de concreto armado e de concreto protendido - Procedimento. Rio de Janeiro.

Debs, M. K., Takeya, T. (2007), “Introdução às Pontes de Concreto”. Texto de Apoio, Universidade de São Paulo, São Carlos.

Departamento Nacional de Infraestrutura e Transporte.(2004). DNIT 010: Inspeções em pontes e viadutos de concreto armado e protendido - Procedimento. Rio de Janeiro.

Euqueres, P. (2011), “Metodologia de inspeção em estruturas de pontes de concreto armado”, Dissertação de Mestrado em Engenharia Civil, Universidade Federal de Goiás, Goiânia.

Laner, F. J. (2001). "Manifestações Patológicas nos viadutos, pontes e passarelas do município de Porto Alegre”. Dissertação de Mestrado em Engenharia Civil, Universidade Federal do Rio Grande do Sul.

Milititsky, J., Consoli, N. C., Schnaid, F. (2015), "Patologia das Fundações”. Oficina de Texto, São Paulo.

Pinheiro, M. R. A.; Silva, E. I. (2018), “Considerações a respeito das principais manifestações patológicas em pontes de concreto armado na cidade de Recife”. $3^{\circ}$ Simpósio Paranaense de Patologia das Construções ( $3^{\circ}$ SPPC), artigo 3SPPC1020, pp. 220 - 232.

Sartorti, A. L. (2008), "Identificação de patologias em pontes de vias urbanas e rurais no município de Campinas - SP”, Dissertação de Mestrado, Universidade Estadual de Campinas, Faculdade de Engenharia Civil e Arquitetura.

Silva, E. C. V., Neto, E. R., Lima, F. B., Moraes, K. A. M. (2018), “Análise das Manifestações Patológicas: Um estudo de caso da ponte sobre a Laguna de Roteiro-AL” em: Congresso Técnico Científico da Engenharia e da Agronomia - CONTECC'2018.

Souza, V. C. M., Ripper, T. (2005), “Patologia, recuperação e reforço de estruturas de concreto”. PINI, São Paulo.

Valentim, L. (2020), “Cai proteção lateral de ponte sobre o rio Canindé em Oeiras". Disponível em: < https://www.muraldavila.com.br/noticias/cai-parte-de-protecao-lateral-de-ponte-sobre-o-rio -caninde-em-oeiras-76193.html > Acesso em: 15 jun 2021.

Vitório, J. A. P. (2002), “Pontes rodoviárias: fundamentos, conservação e gestão”. CREA-PE, Recife. 140p. 